\title{
Dual Pump Recovery (DPR) System to Extract Freshwater in Coastal Aquifers
}

\author{
C. Otto \\ CSIRO Petroleum, Private Bag, PO Wembley, \\ WA 6014, Australia
}

\author{
نظام استعادة الضخ المزدوجة لاستخلاص المياه العذبة من الأحواض الجوفية \\ الساحلية \\ كلوس اوتو
}

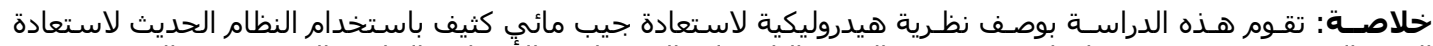

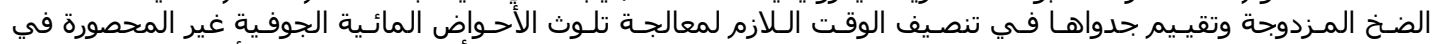

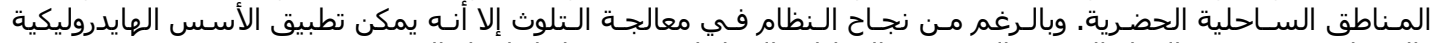
والتقنيات في سحب المياه الجوفية العذبة من المناطق نجاح الساحلية دون تداخل لمياه البحاه البحر.
\end{abstract}

\begin{abstract}
The paper describes the hydraulic theory of recovering a dense plume using a newly devised dual pump recover system (DPR) and its feasibility to half the remediation time of a contaminated unconfined aquifer in a coastal urban environment. Although the DPR system was successfully applied to clean up the polluted aquifer, the hydraulic principles and techniques are also applicable to extract fresh groundwater from coastal aquifers without the risk of saltwater incursion.
\end{abstract}

Keywords: Dual Pump Recovery, coastal aquifer, unconfined aquifer, saltwater intrusion, plume, freshwater, recharge, groundwater.

$\mathbf{T}$ The concept of a DPR system is simple and not new. Similar techniques have been used or have been proposed to prevent upconing of the seawater wedge in coastal aquifers (Underhill and Atherton, 1964; Zack, 1988), recovery of dense coal tar wastes (Villaume et al., 1983) and recovery of light oils, which float on the water table (Wisniewski et al., 1985).

The principles of operating a DPR system are as follows: In essence, where there is a sharp interface between two layers in an aquifer, with distinctly different characteristics (e.g. density stratification, or even a difference in chemical composition which is insufficient to cause density stratification), each layer can be recovered separately by positioning two pumps within a single fully-penetrating screen, with the ratio of pumping in the two pumps equal to the ratio of the transmissivities in the two layers. A fully penetrating screen has the advantage that well losses are markedly reduced, thus there is minimal drawdown of both the water table and the interface in the near field of the bore. Radial flow towards the bore is essentially horizontal at a small distance from the bore, and the two types of water are drawn into the screen and separated within the screen by being drawn upwards or downwards towards the control and recovery pumps, respectively. There is little or no mixing of the two types of water within the screen, because a stagnation point exists between the two pumps, i.e. a point where the net velocity is zero.

\section{Dual Pump Receovery System}

A DPR system consists of a pair of "recovery" and "control" pumps that can be used to recover dense and/or contaminated groundwater in an aquifer that contains two distinct layers of water. The recovery pump is the lower pump, and the control pump is the upper pump. The role of the control pump is to balance the rate of extraction from the recovery pump, so as to ensure that contaminated water enters the recovery 
pump and relatively uncontaminated water enters the control pump. Let $Q_{r}$ be the rate of pumping in the recovery pump, and $Q_{c}$ be the rate of pumping in the control pump.

The intake of the recovery pump is located in the contaminated zone or saline interface, as close to the base of the aquifer as practicable, and the intake of the control pump is located as high as possible, perhaps limited by drawdown of the water table. An appropriate choice of pumping rates will cause contaminated water to be removed through the recovery pump and freshwater to be removed through the control pump. The efficiency of the DPR system depends on choosing a combination of pumping rates so that the capture zones of the two pumps meet at (or just below) the elevation of the interface in the far field, i.e. where horizontal flow occurs. When $Q_{C}$ is too low the concentration in the recovery pump will be diluted by freshwater, whereas when $Q_{c}$ is too high, the control pump will be extracting more contaminated water than necessary. Local variations in flow patterns within the near field will cause the interface to move, but it is the position of interface in the far field which is most important.

Conventional recovery in a layered aquifer mixes the water recovered from each layer and requires all recovered water to be treated. DPR recovers two separate types of water: contaminated water from depth which must be treated, and fresh water from near the water table which is clean enough that it can be safely recharged to the aquifer a short distance away. Since the water from the control pumps can be recharged, it is possible to pump at a larger total rate at each DPR site without adversely affecting the water balance of the region. As a result, the plume is recovered more quickly. Furthermore, the water sent for treatment is not diluted by overlying fresh water, the volume of water to be treated is less, and water treatment costs are therefore reduced.

\section{Pumping Rates}

Recovery of the contaminant is controlled adaptively by varying the ratio of pumping from the two pumps. Therefore, a key issue is the appropriate selection of pumping rates. If at any stage the pumping rate of the control pump is too small, the concentration of recovered groundwater from the recovery pump will start to decrease. Conversely, if the pumping rate in the control pump is too large, the concentration of groundwater in the control pump will start to increase, thus limiting re-use and perhaps requiring treatment of the control water. During the operation of a DPR system, concentrations at the pump outlets need to be monitored frequently and pumping rates must be adjusted to changes in concentrations (or elevations of the interface in the far field), so as to maximize the efficiency and the rate of mass recovery of contaminated groundwater at all times.

Results of field trials are described in Otto and Townley, 1997.

\section{Conclusions}

The DPR system can also be used to pump fresh groundwater from a coastal aquifer near the freshwatersaltwater interface. In this case the recovery pump functions as the control pump, and the control (upper) pump is the recovery pump, which delivers the fresh water to the drinking water scheme. The saline water from the control (lower) pump can be discharged back to the marine environment.

\section{References}

Otto, C.J. and L.R. Townley. 1997. Feasibility of a dual pump recovery (DPR) system to recover a dense plume of contaminated groundwater. Chilton, J. et al., Nottingham. Balkema. 513-516.

Underhill, H.W. and M.J. Atherton. 1964. A coastal groundwater study in Libya and a discussion of a double pumping technique. J.Hydrology 2:52-64.

Villaume, J.F., P.C. Lowe, and G.P. Lennon. 1983. Coal tar recovery from a gravel aquifer, Stroudsburg, PA. Proc. ASCE Conf on the Disposal of Solid, Liquid and Hazardous Wastes. Bethlehem, Pennsylvania, April.

Wisniewski, G.M., G.P. Lennon, J.F. Villaume, and C.L. Young. 1985. Response of a dense fluid under pumping stresses. Toxic and Hazardous Wastes, Proc. 7th Mid-Atlantic Waste Conf.

Zack, A.L. 1988. A well system to recover usable water from a freshwater-saltwater aquifer in Puerto Rico. U.S. Geological Survey Water-Supply Paper: 2328.

Received October 2002.

Accepted November 2002. 